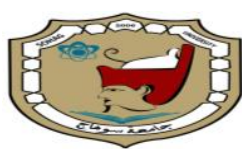

Sohag University

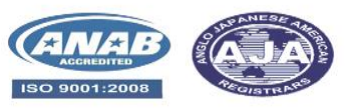

Sohag Medical Journal

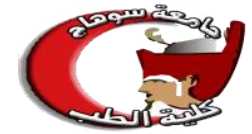

Faculty of Medicine

\title{
Identification of sex from the sternum bone and the role of C.T in sex estimation
}

\author{
Shaima Ali Allam, Reda Mohamed Elsayed, Ahmed Mohamed Said, \\ Suhair Ali Muhammed.
}

Department of Forensic Medicine and Clinical Toxicology, Faculty of Medicine, Sohag University.

\begin{abstract}
:
Personal identification is a subtle perception and often one of the most significant priorities in the investigation of criminal cases, mass disasters, and forensic concerns. Sex determination is an important step in personal identification which can be done from bones examination either from their metric measurements or radiograph images especially in difficult identification as dismemberments, mutilations and explosions. In such cases, the forensic examiner can depend on bone measurements. The best result of sex determination is achieved by accessing the entire skeleton, Skeletal remains traditionally used for gender identification (pelvis, long bones, and skull) are commonly restored in fragmented or states. When the entire skeleton is present, identification of age and sex can be done with $80 \%$ to $100 \%$ accuracy. The sternum is one of these bones which are being commonly used for sex identification either by direct measurement of dried sternum bones from dead bodies or indirect measurement of images taken from chest radiographs. Studies on sternal length for sex determination were done mostly on cadaveric dissections and recently some studies have utilized radiological measurements also.
\end{abstract}

Keywords: Sternal measurements; Sexual dimorphism, Identification from the bone.

\section{Introduction:}

Identification of unknown human remains is one of the most important goals of any forensic medical investigation. To confirm the identity, we must estimate the biological profile of the individual which includes determining the age, gender, height, and other anthropological criteria. Skeletal remains of the human are often examined in cases of advanced decay and charred or mutilated bodies. ${ }^{(1 a n d 2)}$ Personal identification is often observed as a need for unknown remains after natural disasters, such as earthquakes, floods, and landslides. Personal identification may also be needed in the case of man-made disasters which consist of terrorist attacks, mass murders or bomb blasts, as well as when a body is purposely dismembered in a manner that may conceal the identification. ${ }^{(3)}$

The process of identifying an individual from decomposed body parts, or skeletal remnants represents a difficult process in forensic medicine despite the rapid advances in different diagnostic methods. (4and5)

Since forensic anthropologists frequently receive incomplete skeletons, and skeletal remains can be preserved over centuries, an area where alternate methods of identification should be researched for sex estimation. ${ }^{(4,6)}$

\section{Importance of sex identification:}


Sex identification, as well as age, and ethnicity play important roles in identifying an unknown individual. Sex identification specifically remains a crucial aspect of identifying unknown human remains in forensic medicine, particularly when it is not possible to obtain whole skeletons or remains for analysis. ${ }^{(7)}$

If an investigator is able to accurately predict the sex of unknown skeletal remains, it would further focus the search of missing person's files, as it narrows down the field of possible identifications to half of the sample (8) This can vastly shorten the work of an investigator by decreasing the number of antemortem records to be retrieved for comparison with the unknown remains. (9) Discriminant function analysis is increasingly used to determine the gender of a skeleton. The method is a reliable one, decreases the examiner's subjective opinion, and is reproducible. But the results obtained from the analysis of the discriminant function of sex determination for the specific population cannot be applied to other geographical areas due to the diversity of the population. Therefore, there is a need for the development of population-specific discriminant function analysis. ${ }^{(10)}$ There are vast techniques that may be applied in an attempt to identify unknown human remains including deoxyribonucleic acid (DNA) matching, fingerprint analysis, radiological and anthropological methods.(11) Technologies such as DNA fingerprinting and molecular methods are very sophisticated and require updated equipment and skilled operators. These methods have a greater degree of reliability but are invasive, complex and highly expensive, and time-consuming. (12)

The best result of sex determination is achieved by accessing the whole skeleton, but in most cases the skeleton is incomplete. Therefore, various local s- keletons like the sternum (13), pelvis, patella, skull, and its parts have been used for sex determination in different populations around the world. (14and15) In a forensic investigation, identification plays one of the most important parts. Bones when they are available are an important element of identification. There are differences between males and females including skeletal differences along with hormonal and physiological differences are in total known as sexual dimorphism. When the skeleton has partially recovered, it is essential to make a diagnosis from $t$ he available parts. In these cases, fine differences also assume importance. (16and17)

\section{Sex identification from the sternum:}

The sternum located in the middle of the anterior thoracic cage is often used in forensic anthropological contexts. As being a flat bone that can survive a great degree of compression (16and17)

The sternum is one of the bones that are used to determine sex on a wide range either by direct measurement of dried sternum bones from corpses or indirect measurements of images taken from chest radiographs (18). This attributed to the that the sternum may be preserved in an integral form even in the case of massive skeletal destructtion, because of its relatively protected position in the body, so studies performed on it may be more beneficial than the other bones of the body (19). The sternum has attracted significant interest in studies of sexual dimorphism $(17,20)$.

In addition to the use of sternum to determine the sex, it was also used to determine age and height in forensic examinations. (21and22)

Many studies analyze the applicability of Hyrtl's law to determine the sex from the sternum. Which states that the 
length of the mesosternum is more tha$\mathrm{n}$ twice the length of the manubrium in both males and females. (23)

Several researchers have investigated different linear dimensions of the manubrium and mesosternum in many populations and have reported that they are sexually dimorphic, resulting in the establishment of high diagnostic values for assessing bone sexuality. (24)

(Hunnargi et al., 2008) reported that the reliability of sternum is more than $80 \%$ in males and more than $75 \%$ in females in a Maharashtrian population of India, on the other side (Macaluso, 2010) found the accuracy of more than $80 \%$ in a sample from South African. (Franklin et al., 2012) reported an accuracy of $80.0 \%$ in males and of more than $85 \%$ in females on American whites and black estimating sex of Australian sternum. There is a need to prepare criteria for different populations because differences in sexual dimorphism are specific to each population (23,25).

According to the Forensic Anthropology Data Bank (FDB), which showed an inventory of skeletal remains including more than 1000 cases, the rate of the manubrium and sternum recovery is more than $59 \%$. These data indicate that the sternum is a potentially useful structural component in forensic anthropological analyses (26and27) Previous studies on sternal lengths for sex determination were done on various populations like South African Blacks (28), Spaniards (29), and Japanese. (24) Studies on sternal length for sex determination were done mostly on cadaveric dissections and recently some studies have utilized radiological measurements also. The accuracy of radiological measurements which have been done on different ethnic populations can only be utilized in practical forensic medicine when we have obtained validated data from different populations of the world. ${ }^{(30)}$

Quantification of the presence of sexual dimorphism of the sternum has been attempted using various methods, including morphotropic evaluation of sexually dimorphic features. ${ }^{(31) .}$

Other published reports used morphometric measurements and statistical analysis using either bones or radiographs. ${ }^{(23,29,32)}$

\section{Role of CT in sex identificati- on:}

Newer technologies such as computed tomography (CT) and two-dimensional (2D) and three-dimensional (3D) scaning have advantages in estimating sex. They are easy to use, quick to implement, and more objective than methods that evaluate qualitative characteristics (33,34).

Computerized tomography (CT) has been used for several years in clinical areas such as traumatology and oncology. In recent years, it has also been used by some departments of forensic pathology as a supplement to forensic autopsies. (35and36).

Computed tomography (CT) provides an opportunity for 3D imaging of the skeletal system from scans during clinical examination of known individuals. In addition, computed tomography allows investigation of anatomical areas that are not readily available by autopsy and allows fractures and internal organs to be seen "in situ". (37)

Multi-detector CT scans can give fast and accurate results in identifying victims of mass disasters and legal causes. It can be effectively used for the analysis of skeletal structures, it provides clear and unmistakable images in different areas without distortion or interference with other anatomical structures, it is able to distinguish fine details from conventional radiography, it 
is able to provide a slice with a thickness of $1 \mathrm{~mm}$ or less. ${ }^{(38)}$

\section{Conclusion:}

The sternum is frequently used in forensic anthropological contexts. As being a flat bone that can survive a great degree of compression. In addition to its use to determine sex, the sternum was also used for estimating age and height in forensic cases.

\section{References:}

1. Giurazza F, Del Vescovo R, Schena E, Battisti S, Cazzato R, Grasso F. Determination of stature from skeletal and skull measurements by CT scan evaluation. Forensic Sci. Int. 2012;3:222-298.

2. Lee S, Gong H, Hyun J, Koo H, Lee H, Chung N. Estimation of stature from femur length measured using computed tomography after the analysis of three-dimensional characteristics of the femur bone in Korean cadavers. Int. J. Legal Med. 2017;131(5):1355-1362.

3. Tiwari P, Bhovi TV, Jaju PP, Gupta M, Shrivastava K. Frontal sinususeful personal identification tool, Journal Of Oral Medicine, Oral Surgery, Oral Pathology and Oral Radiology 2016;2:11-22.

4. Sharma SK, Jehan M, Kumar A. Measurements of maxillary sinus volume and dimensions by computed tomography scan for gender determination, JASI 2014;63:36-42.

5. Ahmed AG, Gataa IS, Fateh SM, Mohammed GN. CT scan images analysis of maxillary sinus dimensions as a forensic tool for sexual and racial detection in a sample of Kurdish sample. European Scientific Journal 2015;11:272-281.

6. Akhlaghi M, Bakhtavar K, Moarefdoost J, Kamali A, Rafeifar
S. Frontal sinus parameters in computed tomography and sex determination. Legal Medicine 2016;19:22-27.

7. Hamed SS, El-Badrawy AM, Fattah SA. Gender identification from frontal sinus using multi-detector computed tomography, Journal of Forensic Radiology and Imaging 2014; 2:117120.

8. Mathur H, Mathur A, Ahmed J, Khorate M, Tripathi P. Conventional frontal sinus imaging in the identification of sex, In a population of Udaipur city, India. J. Med. Sci. Clin. Res. 2013; 1:33-37.

9. Goyal M, Acharya AB, Sattur AP, Naikmasur VG. Are frontal sinuses useful indicators of sex? J. Forensic Leg. Med. 2013; 20:91-94.

10.Kanchan Kumar P, Vaibhav P, Madhukar P, Marchand N, Kamdi Y, Sumit T., et al., Estimation of stature from the head length \& head breadth in central Indian population: an anthropometric study. Int. J. Anat. Res. 2015; 3(1):954-957.

11.Kanthem R, Guttikonda V, Yeluri S, Kumari G. Sex determination using maxillary sinus. Journal of Forensic Dental Sciences 2015; 7:163-164.

12.Rosing FW, Graw M, Marre B, Ritz-Timme S, Rothschild MA, Rotzscher,K. et al., Recommendations for the forensic diagnosis of sex and age from skeletons. Homo 2007; 58(1):75-89.

13.Chandrakanth H, Kanchan T, Krishan K. Osteometric analysis for sexing of modern sternum - An autopsy study from South India. Legal Med. 2014; 16(6):350-356.

14.Peckmann TR, Orr K, Meek S, Manolis SK. Sex determination from the calcaneus in a 20th-century Greek population using discriminant function 
analysis. Science \& Justice 2015; 55:377-382.

15.Didi AL, Azman RR, Nazri M. Sex determination from carpal bone volumes multi-detector computed tomography (MDCT) study in a Malaysian population, Legal Medicine 2016; 20: 49-52.

16.Fernandez ED, Saez AS, Moro JI. Anthropological determination of sex by studying the sternum. The University of São Paulo Nursing School Journal 2007; 6:1-16.

17.Hungary SA, Menezes RG, Kanchan T, Lobo SW, Binu VS, Uysal S. et al., Sexual dimorphism of the human sternum in a Maharashtrian population of India: a morphometric analysis. Legal Med. 2008; 51:162167.

18.Torwalt CR, Hoppa RD. A test of sex determination from measurements of chest radiographs. J. Forensic Sci. 2005; 50:785-790.

19.Saraf A, Kanchan T, Krishan K, Ateriya N, Setia $\mathbf{P}$. Estimation of stature from sternum - Exploring the quadratic models. Journal of Forensic and Legal Medicine 2018; 58:9-13.

20.Gautam RS, Shah GV, Jadav H, Gohil BJ. The human sternum-as an index of age and sex. J. Anat. Soc. India 2003; 52(1): 20-23.

21.Menezes RG, Kanchan T, Kumar GP, Rao PP, Lobo SW, Uysal S., et al., Stature estimation from the length of the sternum in South Indian males: a preliminary study. J. Forensic Leg. Med. 2009;16: 441-443.

22.Chandrakanth HV, Kanchan T, Krishan K, Arun M, Pramod Kumar GN. Estimation of age from human sternum: an autopsy study on a sample from South India. Int. J. Legal Med. 2012; 126:863-868.

23.Bongiovanni R, Spradley MK. Estimating sex of the human skeleton based on metrics of the sternum. Forensic Sci. Int. 2012; 219(1-3):290297.

24. Torimitsu S, Makino Y, Saitoh H, Sakuma A, Ishii N, Inokuchi G., et al., Estimation of sex in Japanese cadavers based on sternal measurements using multidetector computed tomography. Legal Medicine 2015; 17(4), 226-231.

25.Konigsberg LW, Algee-Hewitt B, Steadman DW. Estimation and evidence in forensic anthropology: sex and race. Am. J. Phys. Anthropol. 2009; 139:77-90.

26.Claus M, Tomicic Z. Discriminant function sexing of fragmentary and complete tibiae from medieval Croatian sites. Forensic Sci. Int. 2005; 147:147152.

27.Barrio PA, Trancho GJ, Sánchez JA. Metacarpal sexual determination in a Spanish population. J. Forensic Sci. 2006; 51: 990-995.

28. Macaluso PJ. The efficacy of sternal measurements for sex estimation in South African blacks. Forensic Sc.i Int. 2010; 202(111): 1-7.

29.Macaluso PJ, Lucena J. Estimation of sex from sterna dimensions derived from chest plate radiographs in contemporary Spaniards. Int. J. Legal Med. 2014; 128:389-395.

30.Soumeek C, Priyam R, Arkadeep D, Saikat D, Ritwik G. A Study for the determination of sex by multidetector computed tomography of sternum using discriminant function and logistic regression. Arab Journal of Forensic Sciences \& Forensic Medicine 2019; 1(10):1445-1454.

31.Singh J, Pathak RK. Morphometric sexual dimorphism of the human sternum in a north Indian autopsy sample: sexing efficacy of different statistical techniques and a comparison with other sexing methods. Forensic Sci. Int. 2013; 228:174.184. 
32.García-Parra P, Pérez Fernández Á, Djorojevic M, Botella M, Alemán I. Sexual dimorphism of human sternum in a contemporary Spanish population. Forensic Sci. Int. 2014; 244:313-319.

33.Garvin HM, Ruff CB. Sexual dimorphism in skeletal brow ridge and chin morphologies was determined using a new quantitative

method. Am. J. Phys. Anthropol. 2012;147:661-670.

34.Djordjevic M, Roldan C, GarcíaParra P, Aleman I, Botella $M$. Morphometric sex estimation from 3D computed tomogram-mph of coxae model and its validation in skeletal remains. Int. J. Legal Med. 2014; 128:879-888.

35.Levy AD, Abbott RM, Mallak CT, Getz JM, Harcke HT, Champion HR. Virtualautopsy: preliminary experience in high-velocity gunshot wound victims. Radiology 2006; 240:522-528.
36.Poulsen K, Simonsen J. Computed tomography as routine in connection with medico-legal autopsies. Forensic Science International 2007; 171(23):190-197.

37.Decker SJ, Davy-Jow SL，Ford JM, Hilbelink DR. Virtual determination of sex: metric and nonmetric traits of the adult pelvis from 3D computed tomography models. J. Forensic Sci. 2011; 56(5):1107-1114.

38.Sidler M, Jackowski C, Dirnhofe RR. Use of multislice computed tomography in disaster victim identification: advantages and limitations. Forensic Sci. Int.2017; 169(2-3):118-128. 